\title{
O GÊNERO TRAILER COMO FERRAMENTA NO PROCESSO ENSINO- APRENDIZAGEM DE LÍNGUA ESTRANGEIRA
}

\author{
Flávia Brocchetto Ramos - Doutora em Letras pela PUCRS. Pós-doutora em Educação pela UFMG. Docente na Universidade de \\ Caxias do Sul no Programa de Pós-Graduação em Letras (Doutorado), no Programa de Pós-graduação em Educação (Mestrado) e no \\ Curso de Letras e Pedagogia. Bolsista CNPq. \\ E-mail: $\underline{\text { ramos.fb@gmail.com }}$ \\ Lisiane Ott Schulz - Mestre em Educação pela UCS. Graduada em Letras pela UFRGS. Professora do Programa de Línguas \\ Estrangeiras da Universidade de Caxias do Sul. \\ E-mail: ottoschulz@gmail.com
}

\section{Resumo}

Neste artigo, analisamos o trailer do filme Rio à luz da teoria enunciativa de Bakhtin e, a partir desta perspectiva, sugerimos que esse gênero discursivo esteja presente nas aulas de língua estrangeira.

\begin{abstract}
In this article, we analyze the movie trailer Rio through Bakhtin's theory of the utterance. From this perspective, we then suggest that this speech genre be used in foreign language classes.
\end{abstract}

Cada enunciado é um elo da cadeia muito complexa de outros enunciados.

Bakhtin

\section{1) Introdução}

A forma como o professor age em sala de aula reflete sua concepção de língua e linguagem. Aliás, as nossas ações estão pautadas em pressupostos que revelam nosso lugar no mundo. Assim, apresentamos, inicialmente, um breve panorama de como a linguagem é entendida segundo a visão behaviorista e a cognitivista e a influência dessas correntes epistemológicas na prática pedagógica. A seguir, descrevemos de maneira objetiva a concepção de linguagem na visão sociointeracionista de Vygotsky (2007, 2008) e na visão enunciativa de Bakhtin (1997, 2003). Por fim, apresentamos nossa compreensão dos gêneros discursivos trailer e filme como enunciados que estabelecem diálogo com enunciados anteriormente produzidos e que suscitam respostas futuras. O foco deste artigo é, portanto, a análise do trailer do filme de animação Rio, de Carlos Saldanha, segundo os conceitos de enunciado e de gênero de Mikhail Bakhtin (1997, 2003) e as possibilidades de apropriação desse trailer pelos telespectadores. Nesse ponto do estudo, apresentamos uma biografia concisa do diretor do filme e uma contextualização da película. A seguir, trazemos uma análise do trailer como enunciado e finalizamos com uma reflexão sobre como o uso de trailers pode servir de ferramenta de mediação no processo de ensino e aprendizagem da lingua estrangeira. 


\section{2) Concepções de linguagem e sua influência na ação docente}

Segundo Hall e Verplaetse (2000, p. 1), na concepção behaviorista estrutural, "a linguagem é vista como um conjunto de sistemas linguísticos exteriores ao aprendiz e a aprendizagem como um processo de assimilação de componentes estruturais desses sistemas em estruturas mentais pré-existentes"1. Nessa perspectiva, aprendemos a língua através da repetição, memorização e automatização de estruturas básicas. A aprendizagem, nesse entendimento, pode ser controlada por fatores externos ao indivíduo. O método audiolingual, que surgiu em meados de 1950, é um exemplo de prática pedagógica sustentada por essa concepção. Na aula delineada por essa abordagem de ensino, a aprendizagem ocorre predominantemente sob o controle do professor. Seu papel é ajudar o aprendiz a desenvolver bons hábitos linguísticos, como também evitar que ele cometa erros. Para tanto, ele deve controlar a produção oral e escrita do aluno e oferecer modelos linguísticos. Frequentemente, as aulas planejadas de acordo com o método audiolingual apresentam três fases: Presentation, Practice and Production (PPP). O ensino é centrado na língua, ou seja, os exercícios propostos aos alunos têm como foco a forma da língua e não o sentido dos enunciados. O professor, utilizando-se da técnica do substitution drills, apresenta estruturas gramaticais e itens de vocabulário pré-selecionados que devem ser repetidos pelos alunos até a memorização e consequente internalização. Os behavioristas acreditam que a aprendizagem é essencialmente individual e que ocorre de fora para dentro do indivíduo.

O paradigma behaviorista predominou por muitos anos, mas foi contestado a partir dos estudos de Noam Chomsky. Esse linguista (1998) argumenta que o ser humano possui uma faculdade inata da linguagem, ou seja, a língua emerge de um "estado inicial". Ao ser exposto à língua, o homem ativa o Dispositivo de Aquisição da Linguagem $(D A L)$ que permite selecionar as regras e normas que se aplicam a sua comunidade linguística e refutar outras. A partir desse estado inicial ou dessa Gramática Universal e da ativação do $D A L$, o homem desenvolve a linguagem. Chomsky mostra-se contrário ao ensino através de repetições e de memorizações e ressalta o aspecto criativo da língua.

Influenciado pelos pressupostos cognitivistas de Chomsky, Stephen Krashen (1982, 1985) desenvolveu uma teoria de aquisição da linguagem. Para ele (1982, p. 3), "a aquisição da língua ocorre quando a língua é usada com o fim a que se destina, a comunicação." Ao propor uma distinção entre aprendizagem (fenômeno consciente) e aquisição (fenômeno inconsciente), Krashen (1985) insiste que a aprendizagem não se transforma em aquisição através da prática da língua ou da correção de erros e que o aprendiz só adquire uma língua estrangeira quando exposto ao insumo compreensível do tipo $i+1$, isto é, insumo um pouco além do estágio atual de competência linguística do aprendiz. Krashen, fundamentado em Chomsky, acredita que existe uma ordem natural de aquisição de estruturas gramaticais da língua que pode ser inclusive previsível. 
Entre as décadas de setenta e oitenta, do século XX, o cognitivismo ganha força. Nesse momento, segundo Pinto (1999, p. 119), “o aluno passou a ser visto como processador ativo de informação, um intérprete, um sintetizador que utiliza uma variedade de estratégias para armazenar e recuperar a informação”. O erro, nessa concepção, já não é mais visto como algo que deve ser evitado, mas como parte do processo de aprendizagem.

Na perspectiva sociointeracionista de Vygotsky $(2007,2008)$ e na visão enunciativa de Bakhtin (1997, 2003), a linguagem não tem apenas a função de comunicar e não é individual somente. Ela é um instrumento que permite a prática social e ideológica. Esse instrumento ou ferramenta constitui o sujeito e é constituída por ele, isto é, o homem se constrói, se reconstrói e se coconstrói através da linguagem. É a linguagem que permite a reflexão e a construção de conhecimento e sentidos de forma sempre dialógica e dinâmica. Nesse sentido, discorrendo sobre a linguagem, Franchi destaca que

antes de ser para a comunicação, a linguagem é para a elaboração; e antes de ser mensagem, a linguagem é construção do pensamento; e antes de ser veículo de sentimentos, idéias, emoções, aspirações, a linguagem é um processo criador em que organizamos e informamos as nossas experiências. (1992, p. 25)

Pelo exposto, e fundamentados em Vygotsky (2007, 2008) e Bakhtin (1997, 2003), é possível afirmar que somos seres de linguagem, o homem é também a sua linguagem. Levando em conta o caráter dialógico, social e interativo da linguagem, percebemos o aluno como um ser social, efetivamente discursivo e que reconhece o outro e compartilha conhecimento, experiências e opiniões por meio da linguagem, e a sala de aula como um ambiente social onde tanto as vozes discentes quanto a docente se fazem presentes e necessárias.

Vygotsky (2007, 2008), um dos principais representantes da teoria sociointeracionista, sustenta que o desenvolvimento cognitivo do ser humano ocorre durante suas interações com o mundo social e material, mas sempre é mediado pela linguagem. Na verdade, ele propõe a articulação entre pensamento e linguagem e ainda a concepção de linguagem como um elemento mediador entre o ser humano consigo mesmo e com seu entorno. A linguagem é fundamental para a pessoa se constituir, se conhecer e pensar sobre si e sobre seu entorno. As pessoas que se valem da linguagem verbal, por exemplo, pensam por meio dessa ferramenta. Pensam com palavras, sentenças, cujo significado é entendido, para o autor, como um ato do pensamento (2008, p. 6). Na verdade, o significado pertenceria tanto ao domínio da linguagem quanto ao do pensamento e este significado assim como o ser humano são dinâmicos.

A linguagem também é pensada numa perspectiva sociointeracionista por Bakhtin (1997, 2003). Para esse estudioso,

a verdadeira substância da língua não é constituída por um sistema abstrato de formas linguísticas nem pela enunciação monológica isolada, nem pelo ato psicofisiológico de sua produção, mas pelo fenômeno social da interação verbal, realizada através da 
enunciação, ou das enunciações. A interação verbal constitui assim a realidade fundamental da língua." (BAKHTIN, 1997, p. 123, grifo do autor).

Corroboramos com as ideias de Vygotsky e Bakhtin de que a língua é produto de uma atividade social, ou seja, é resultado da interação entre os locutores.

As ações dos professores de língua estrangeira que contemplam essa visão tentam privilegiar o envolvimento discursivo do aluno na construção do conhecimento e da linguagem e proporcionar tarefas em que os discentes interajam, reflitam e criem. Isso significa que a linguagem não é trabalhada em segmentos isolados ao seu contexto de produção. A sala de aula pensada nessa perspectiva é um local no qual as interações sociais são incentivadas e as construções são coletivas.

Outro ponto a ser considerado a partir das contribuições bakhtinianas são as manifestações de linguagem com as quais os sujeitos estão em contato. Como seres de linguagem que somos, nos inserimos num universo povoado por manifestações discursivas. Não temos, pois, o privilégio de sermos um falante inaugural, mas nos apropriamos de formas discursivas já existentes e podemos até transformá-las. Aliás, Bakhtin (2003, p. 300) lembra que só o Adão mítico teria usado a palavra inaugural.

Se vivemos num mundo povoado por linguagem e os modos de interação vão sendo alterados porque os modos de viver também vão se modificando, nada mais certo que determinadas formas de comunicação se extingam e outras apareçam. Tecnologias de comunicação como o telégrafo e o telex entram em desuso com o surgimento do correio eletrônico e das ferramentas de comunicação simultânea como o MSN e o Skype

Também no universo da indústria cultural, por exemplo, novos produtos ou modalidades discursivas são lançadas para atender as demandas de entretenimento da infância e da adolescência contemporânea. Nestas últimas décadas, tem havido um investimento maciço na produção de filmes para esse público, em especial os filmes de animação gráfica, dentre os quais podemos citar Shrek, Os incríveis, Procurando Nemo, etc. Em comum nesses produtos está a linguagem do desenho animado, em que palavra e imagem dialogam para constituir os enunciados do filme.

Não basta, porém, que estes filmes sejam produzidos com a mais moderna tecnologia e com os melhores recursos e efeitos sonoros e visuais. Eles precisam ser consumidos em larga escala, pois visam altos lucros. Para instigar esse consumo, há uma indústria responsável pela divulgação. E foi com o intuito de divulgar que surgiu o trailer.

\section{3) O filme e o trailer}

Rio é um filme de animação de longa metragem dirigido por Carlos Saldanha, que estreiou mundialmente no dia 08 de abril de 2011 e que tem como pano de fundo a cidade do Rio de Janeiro.

Saldanha é um brasileiro que, aos 22 anos, parte para os Estados Unidos, onde cursa Mestrado em Artes e se especializa em animação digital na School of Visual Arts, em Nova Iorque. Seu trabalho como animador digital ganha destaque a partir do filme 
de animação A era do gelo (2002) no qual atua como co-diretor. Saldanha é também codiretor de Robôs (2005) e diretor de A era do gelo 2 (2006) e A era do gelo 3 (2009) todos lançados pela Twentieth Century Fox e produzidos pela Blue Sky Studios. É considerado um dos animadores digitais mais criativos e talentosos da atualidade, destacando-se também como diretor cinematográfico, produtor e dublador.

O primeiro trailer do filme, disponível na internet, foi lançado em maio de 2010 e tem duração de 2 minutos e seis segundos ${ }^{3}$. Essa modalidade discursiva, presente na contemporaneidade, é aqui entendida como um gênero discursivo ${ }^{4}$.

O termo trailer tem sua origem em uma época em que era tradicionalmente exibido ao término da sessão de cinema, após o filme (SANTOS, 2004). Posteriormente, passou a ser mostrado antes do filme. Como ferramenta de marketing, sua principal finalidade é divulgar outra película a ser lançada em breve e, por isso, várias estratégias de sedução são empregadas para instigar a curiosidade do telespectador. Cenas impactantes, acompanhadas de efeitos sonoros e de música, levam o espectador a se perguntar o que virá a acontecer no enredo da história sendo, dessa forma, seduzido a assistir ao filme. O protagonista é, muitas vezes, deixado em evidência para que haja uma identificação do público com esse personagem.

Vivemos em uma sociedade persuasora, e os meios de comunicação utilizam estratégias discursivas de manipulação como mecanismo de ordenação social simbólica (ROIZ, 2002, p. 100-203). O trailer, como discurso publicitário, pode ser visto como um enunciado que está inserido numa situação enunciativa e, portanto, responde às demandas da sociedade de consumo. Se, por um lado, assume o discurso daquele que gera o produto, por outro, tenta atingir os desejos de consumo do público visado. Enfim, a resposta que o trailer deseja não é um enunciado verbal, mas uma atitude que implica o consumo do filme pelo público-alvo ${ }^{5}$. No caso desse trailer, cenas dramáticas e cômicas se mesclam, a fim de mobilizar o espectador com uma mostra de elementos presentes num filme de animação.

Pensar o trailer como gênero a ser estudado na aula de língua estrangeira, implica buscar estratégias de interação do produto com o aluno. Nesse sentido, mesmo antes de assistir ou de buscar informações adicionais sobre o longametragem, detivemonos apenas nas imagens e nos sons empregados no trailer, sem considerar a linguagem verbal.

$\mathrm{O}$ enredo parece querer provocar surpresa ao espectador ao apresentar uma arara adulta que não sabe voar. A estranheza pode ser um dos fatores que instiga a curiosidade do espectador. Diante da surpresa de ver uma ave adulta que não consegue voar, o espectador mesmo não se detendo ao enunciado verbal em inglês, realizado por Blu (Fig. 1), pode concluir, pelos sons e pela visualidade, tratar-se de um animal domesticado que, por ter sido mantido em cativeiro, é impedido de desenvolver tal habilidade. Essa especulação é confirmada quando Blu, tomada de medo, diz que gostaria de estar em sua gaiola. 
Fig. 1 - Blu estarrecida com o que vê

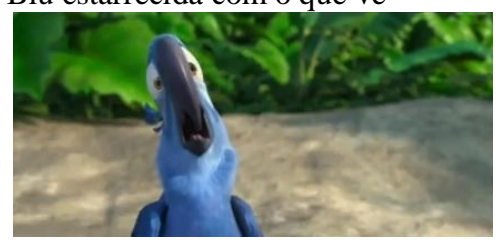

De acordo com informações que constam no sitio da Blue Sky Studios e da IMDB (The Internet Movie Data Base) na Internet, Blu e sua dona Linda recebem a visita de um ornitologista brasileiro que os convence de que Blu, sendo o último macho de sua espécie, precisa ser levado ao Brasil onde encontrará Jewel, a arara azul fêmea. Deixa, então, o conforto de sua gaiola na cidade de Minnesota nos Estados Unidos e viaja para o Rio, a fim de encontrá-la.

O consumidor, ao assistir a um trailer, cria expectativas. Movido pela curiosidade e pelo desejo de descobrir se a ave conseguirá voar e conquistar o coração da arara fêmea, ele provavelmente será levado a consumir o produto.

Cada filme criado num determinado contexto histórico e social é entendido como uma ferramenta cultural. A exibição dessa obra nos cinemas, por exemplo, ocorreu num momento em que o mundo volta seu olhar para o Brasil, um país emergente que sediará tanto a copa do Mundo de 2014 da FIFA 6 quanto os Jogos Olímpicos de 2016. Considerando o contexto em que essa obra, aqui entendida como enunciado, é lançada, retomamos Bakhtin que afirma que nenhum enunciado é neutro, e que expressa juízos de valores e posições ideológicas.

Ao realizar um enunciado, neste caso, produzir um filme, os envolvidos escolhem a voz do discurso e abordam seus pontos de vista. Na verdade, o filme e o trailer são vistos neste artigo, na perspectiva bakhtiniana, como uma resposta a outros enunciados que o precederam. A palavra ou o enunciado nunca é neutro e está inserido na cadeia da comunicação verbal. Cada enunciado é, pois, uma resposta explícita ou implícita às palavras do outro, trata-se de um elo dessa cadeia que pode ser entendido como um momento presente na situação de enunciação. $\mathrm{O}$ espectador, por sua vez, não é passivo, pois conforme argumenta Bakhtin, "toda a compreensão é prenhe de resposta" (2003, p. 271). Dessa forma, tanto o trailer quanto o filme promovem uma "reação responsiva ativa"7 nos sujeitos que o assistem, podendo eles, no caso do trailer, querer ou não assistir a película e, com relação ao filme, concordar ou opor-se as ideias do discurso, as atitudes dos personagens, a representação da realidade mostrada no filme, etc.

\section{4) A linguagem do cinema, o enunciado de Bakhtin e o trailer do filme Rio}

O mundo que nos cerca encontra-se impregnado de sons, imagens, cores, ações e movimento. A linguagem cinematográfica integra todos esses elementos com a finalidade de proporcionar a sensação de que estamos vivenciando os momentos retratados nos filmes. 
Um dos grandes atrativos do cinema incluindo aí também alguns filmes de animação é justamente a criação da ilusão da verdade. Conforme aponta Bernardet, a

ilusão de verdade, que se chama impressão da realidade, foi provavelmente a base do grande sucesso do cinema. $\mathrm{O}$ cinema dá a impressão de que é a própria vida que vemos na tela, brigas verdadeiras, amores verdadeiros. (2000, p. 12, grifo do autor).

Fig. 2 - Piloto de asa delta sobrevoa o Rio

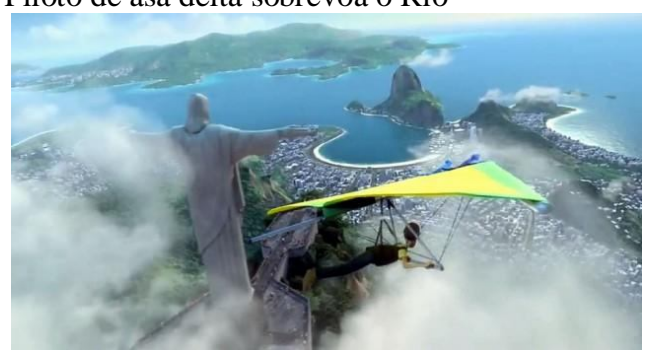

A estratégia ilusionista usada no cinema e agora intensificada através dos recursos em terceira dimensão tem a intenção de envolver o espectador na narrativa da história. No início do trailer de Rio, essa proposição já pode ser sentida. Dependendo do ângulo em que a cena é criada, podemos ter a ilusão de que, pelo menos por alguns instantes, somos o próprio personagem, como no caso do piloto da asa delta - nas cores amarelo e verde, simbolizando o Brasil - que ao saltar sobrevoa a cidade do Rio de Janeiro (Fig. 2). Sob esse ângulo, o espectador tem a impressão ou sensação de que ele está realmente saltando com a asa delta e sobrevoando a cidade maravilhosa.

Fig. 3 - Blu e Jewel em forma de bola de futevôlei.

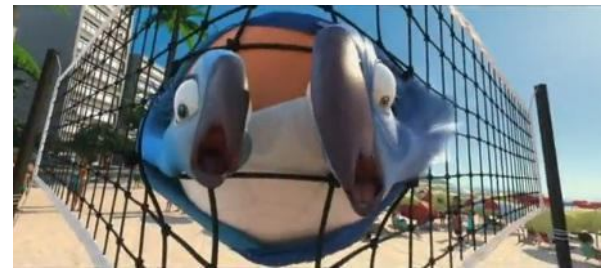

O desejo de mostrar vários pontos de vista presentes no longametragem de animação gráfica implica a seleção de diferentes perspectivas veiculadas no trailer. Assim, outro ângulo privilegiado na peça publicitária é a visão a partir de um sujeito que esteja numa das praias da cidade, através da cena em que as aves se enrolam na bola (Fig. 3). O espectador, neste caso, assume outra perspectiva e parece que vai ser atingido por uma bola que vem em sua direção em alta velocidade.

Em filmes de animação contemporâneos, da mesma forma que a realidade busca ser reproduzida da melhor maneira possível, há também um jogo intenso com o imaginário, ou seja, uma constante fusão entre o real e o fictício. No filme Rio, o cenário para a história é o Rio de Janeiro, uma cidade não fictícia. Recortes da cidade (fragmentos da realidade), porém, são recriados. Assim, podemos ver a pedra da Gávea 
e seus contornos, sobrevoar a mata atlântica, a orla marítima, o Cristo Redentor, o Pão de Açúcar, etc. Entretanto, como em quase todos os filmes de animação, os animais falam, pensam, recordam e planejam ações futuras. São desta forma, antropomorfizados e enfrentam problemas similares aos dos seres humanos no seu convívio social, assim como já acontecia nas fábulas de Esopo, ainda antes de Cristo.

Embora, em nosso cotidiano as imagens e os sons estejam por toda parte, as práticas escolares continuam a enfatizar a linguagem escrita em detrimento da imagética e da paralinguagem, ou seja, aquela que acompanha a linguagem verbal. Segundo Andrade, "atitudes como contato visual (o olhar), entonação de voz, intensidade de som, posturas corporais, gesticulação, ícones, imagens, etc., são formas que podem perfeitamente produzir um enunciado significativo" (2008, p. 66), presente nas práticas educativas, intencionalmente planejadas.

Com o advento da cultura digital, tanto o elemento visual quanto o auditivo vêm ganhando mais força. Como ambos são fundamentais para o entendimento do enunciado, poderiam merecer maior atenção nas práticas escolares. As hesitações, a variação na altura e na intensidade da fala dos personagens, os efeitos sonoros que visam a imitar os ruídos típicos de algumas ações e a trilha sonora escolhida para cada momento são prenhes de sentido.

Lembramos que enunciado, segundo Bakhtin, é "a unidade real da comunicação discursiva" (2003, p. 269, grifo do autor). Pode ser constituído de uma única palavra ou mesmo referir-se a uma obra completa como um romance. $\mathrm{O}$ enunciado diferencia-se da palavra ou da oração por ser considerado irrepetível, isto é, ele é sempre um evento único, existe na situação de enunciação. $\mathrm{O}$ enunciado pressupõe um autor e pelo menos um interlocutor e não se restringe às formas linguísticas. Inclui também as formas não verbais.

As unidades da língua possuem significação, mas não sentido. Somente o enunciado, inserido num contexto socioistórico, possui sentido e esse sentido só pode ser apreendido através das relações dialógicas desse enunciado com outros que o precedem e o sucedem na cadeia de comunicação. Para Bakhtin (2003, p. 272), "cada enunciado é um elo na corrente complexamente organizada de outros enunciados". Por isso, na enunciação, o presente, o passado e o futuro coexistem.

O sentido de uma oração é tão variado quanto os contextos e as intenções nos quais ela se realiza. A oração "Eu consigo", por exemplo, pode significar que a pessoa que a enuncia esteja afirmando que consegue realizar algo. No contexto do trailer, contudo, podemos entender que quando Blu diz "Eu consigo", não está afirmando que consegue voar. Utiliza esse enunciado como forma de convencer-se a si próprio que pode voar e na tentativa de se auto encorajar. Aliás, a afirmação de Blu é uma resposta a outro enunciado que a precedeu, emitido pelo tucano: "E se meus amigos sem pena conseguem, não deve ser difícil".

O dialogismo de Bakhtin deve ser entendido no sentido amplo e não apenas como a interação face a face. Podemos nos referir não somente ao diálogo entre os personagens do filme, mas também ao diálogo entre as músicas que compõem a trilha 
sonora e as imagens, entre um filme com filmes anteriores, entre o filme e seus telespectadores, entre os profissionais envolvidos na produção do filme e entre muitos outros.

Um exemplo de dialogismo entre imagem e som pode ser visto na cena em que o tucano Rafael tenta encorajar Blu a voar. Percebemos a expressão de desespero da arara que já pode ser considerada um enunciado. Esse sentimento é acentuado pela imagem do rosto apavorado do homem (Fig. 4) que salta de asa delta e pelo grito de pavor que emite ao saltar. Nessa mesma cena, há o ruído das chaves caindo de seu bolso e vemos os pés descalços desse homem balançando ao ser levado pela asa delta. Esses elementos atuam no enunciado, ampliando a sensação de desespero e desemparo de Blu.

Fig. 4 - Momento de pavor.

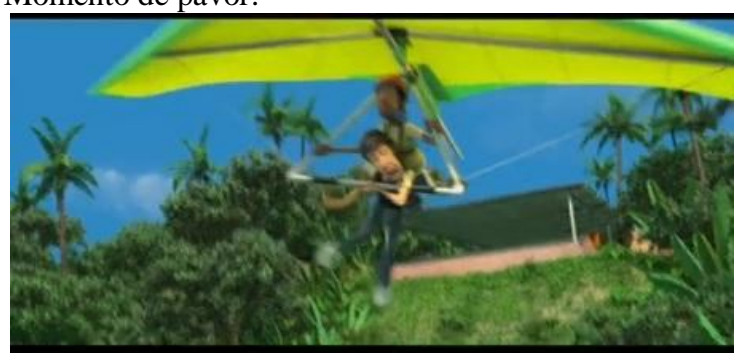

Em entrevista concedida à Moviebox, no Telecine, Carlos Saldanha deixa transparecer a interrelação do filme Rio com outro filme produzido, explicitando o diálogo com outro enunciado que o precedeu. Ele declara que se olharmos para trás, podemos ver que não há muitos filmes de animação que tenham o Brasil como pano de fundo, a não ser o filme do Zé Carioca. A comparação mostra o dialogismo com outro filme que o antecedeu. Zé Carioca, no filme Alô, amigos, de 1942, faz uma turnê com o Pato Donald, a fim de mostrar-lhe o Brasil (Fig. $5^{8}$ ). Zé é carioca, como já diz o nome e leva o Pato a conhecer a cachaça, o samba, etc. De alguma forma, esse filme cujo protagonista é o papagaio Zé, aqui entendido como enunciado, influenciou o enunciado em questão, ou seja, o filme Rio. Na mesma entrevista, Saldanha ressalta que Blu, uma arara que vem dos Estados Unidos descobre a brasilidade através da música, das cores, etc. O Pato Donald também é um americano que queria conhecer o Brasil.

Fig. 5 - Cena do filme Alô amigos, na qual Zé Carioca mostra o Rio ao Pato Donald.

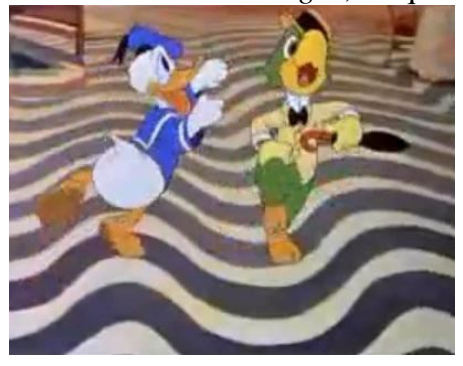

Conforme já mencionado anteriormente, na concepção bakhtiniana, um signo só tem sentido no contexto da enunciação, ou seja, quando se orienta para o outro. Na 
narrativa de um filme, também as imagens podem ser entendidas como signos. Esses só possuem sentido na interrelação com o contexto histórico e social. Assim, no trailer Rio as imagens tais como o sol, a praia, a floresta tropical, os biquínis, a prancha de surf, as frutas e os animais tropicais, remetem os telespectadores à representação que tanto estrangeiros quanto brasileiros tem do Brasil e de seu povo. Enfim, as cores vibrantes usadas nas cenas e o samba que compõe a trilha sonora refletem o estereótipo do brasileiro como um povo alegre, descontraído e festeiro.

O enunciado, dessa forma, não existe fora da relação com o outro (ouvinte, leitor, espectador, etc.) e sem a influência desse sobre o enunciado. Para Bakhtin, o homem se constitui pela linguagem e se coloca no mundo através dela. No ato da enunciação, responde ativamente ao que foi dito e se posiciona. Assim, perguntamos: qual a contribuição que essa história teria na construção do sujeito, neste caso, o espectador.

A partir do trailer do filme Rio, entendemos que a história de Blu é de luta, de coragem e de superação. Blu vai em busca de outro ser de sua espécie, tema recorrente na ficção, presente em contos como "O soldadinho de chumbo", de Hans C. Andersen. Nessa história, Blu precisa superar seus medos e está determinado a fazê-lo. Momentos de tensão são mesclados com outros de alegria, contribuindo para a animação e para a sedução do expectador.

O filme como produto cultural inserido num tempo, é sensível a questões ecológicas. A preocupação contemporânea com a apreensão de animais silvestres é abordada de forma sutil. A arara Blu acredita ser a última ave de sua espécie, quando fica sabendo que existe outra ave como ele no Brasil. Sai do lugar conhecido, enfrenta obstáculos para seduzir essa outra arara numa tentativa de lutar contra a extinção de sua espécie. Várias reflexões podem ser geradas a partir do trailer do filme: a determinação, a busca pela realização de um sonho, a coragem e a superação dos medos (inclusive o medo de ser livre), o valor das amizades, o amor, o respeito pelos animais, a preservação das belezas naturais, o valor de desfrutar a vida, etc. $O$ trailer visa a influenciar o telespectador e a possibilitar que esse adote uma atitude responsiva seja essa a de concordar, refutar ou ressignificar os conceitos apresentados. Outra atitude aqui desejada seria convencer o interlocutor a assistir ao filme.

\section{5) O trailer no processo de ensino e aprendizagem de língua estrangeira}

Na maioria das vezes, ao optar por exibir um filme ou um segmento de filme em nossas aulas de língua estrangeira, preocupamo-nos em apresentar perguntas cujo objetivo é verificar a compreensão da linguagem verbal pelos nossos alunos. Conforme destacam Almeida Filho e El Dash (2002, p. 2), nossa intenção é aferir se o sentido do que está lá no texto oral foi 'apreendido' ou capturado. Esses autores chamam a atenção para o fato de que, em geral, a compreensão oral é muito mais testada do que 'ensinada' ${ }^{\text {' }}$ A preocupação, nesse sentido, é com o produto e não com o processo de construção do sentido. Esclarecem ainda que "o sentido se encontra apenas parcialmente 
no texto" e que "a compreensão não é mero deciframento, nem se limita ao reconhecimento de palavras ou idéias isoladas. Exige "trabalhar" com o insumo para construir um significado".

Bakhtin também não se mostra preocupado com os "processos passivos de recepção e compreensão do discurso no ouvinte" (2003, p. 271), mas com a reação responsiva ativa gerada no outro, já que compreender é responder ao enunciado de um locutor, pois aquele que enuncia dirige-se a alguém e quer resposta. A compreensão é, portanto, sempre dialógica. Compreender é assumir uma atitude em relação ao que nos é exposto.

O processo de compreensão e de construção do sentido vai além da decodificação de símbolos. O sentido não é dado no texto, oral ou escrito, mas no enunciado que é apenas um elo na cadeia da comunicação. Este elo é o ponto de aceitação ou de confronto de opiniões e visões de mundo. Visto dessa forma, não podemos considerar que todos os sujeitos construirão um sentido uno e definitivo ou que reagirão da mesma forma. Por isso, as atividades propostas por professores que contemplam essa visão abrem espaço não apenas a busca da verdade única proferida pelo locutor, mas ao imprevisível, ou seja, ao discurso discente que surge espontaneamente na interação social.

O homem não constrói conhecimento sozinho. É na convivência social que ele vai se constituindo e se desenvolvendo intelectualmente e para que aprenda a estruturar enunciados precisa ter a necessidade de fazê-lo, pois conforme enfatiza Bakhtin (2003, p. 283) "aprender a falar significa aprender a construir enunciados".

Acreditamos que os alunos desenvolvem habilidades comunicativas desde que possam se envolver em interações sociais mediadas pela linguagem, neste caso a língua inglesa. Uma vez que o conhecimento linguístico também é construído no social, pois a linguagem é social, propomos algumas questões, abaixo listadas, que podem ser debatidas em grupos tendo o trailer do filme Rio como recurso didático. ${ }^{10}$

1 Que representação do Brasil em geral, e do Rio de Janeiro mais especificamente, é veiculada no filme Rio? Você concorda com essa forma de representar o Brasil? Por quê ou por quê não?

2 Você acha que esse momento histórico é favorável a exibição de um filme cujo cenário é o Rio de Janeiro? Por quê?

3 Que repercussão o filme pode ter no cenário internacional?

4 Com qual personagem você imagina que os espectadores se identificarão?

5 Que sentimentos podem ser despertados no espectador através desse personagem?

6 Quais são as fobias mais comuns entre as pessoas (claustrofobia, medo de altura, medo de aranhas, baratas etc.)? Que fobia você e seus colegas têm?

7 Você acha que o problema de Blu será solucionado? Se sim, como? Se não, por quê?

8 Quais efeitos especiais mais te seduziram na obra? 
9 De que forma o filme Rio pode ser comparado às histórias de Zé Carioca? Se esse personagem não faz parte do universo de personagens de animação de sua geração, faça uma pesquisa na Internet e relate as diferenças e semelhanças. Se você fosse criar um filme de animação cuja narrativa transcorresse no Brasil, que lugares você escolheria representar? Por quê?

Em síntese, afirmamos, a partir de Larrosa (2002, p. 21) que o conhecimento e a aprendizagem envolvem a experiência. Experiência, conforme argumenta Larrosa, é o que "nos passa, o que nos acontece, o que nos toca". O sujeito da experiência não é "um sujeito que permanece sempre em pé, ereto, erguido e seguro de si mesmo" (op. cit., p. 25), mas um sujeito que é alcançado, que tomba, que é derrubado e que se ergue sempre novamente. O sujeito da experiência é um apaixonado e esta paixão envolve o outro, o alheio. Acreditamos, pois, que a aprendizagem se faz pela interação e pela paixão e, desse modo, a presença do trailer em aulas de língua estrangeira pode ser uma ferramenta para implementar práticas interativas de linguagem que contribuam para a aprendizagem de outra língua.

\footnotetext{
${ }^{1}$ Tradução livre de Lisiane Ott Schulz

${ }^{2}$ Tradução livre de Lisiane Ott Schulz.

${ }^{3}$ Disponível em http://www.youtube.com/watch?v=aRhc6jpQBt0. Acesso em: 25/07/2012

${ }^{4}$ Entende-se que gêneros são "eventos textuais altamente maleáveis e plásticos. Surgem emparelhados a necessidades e atividades sócio-culturais, bem como na relação com inovações tecnológicas (...)" (MARCUSCHI, 2003, p. 19). Nesse sentido, a publicidade infantil é tomada neste texto como um gênero discursivo.

${ }^{5}$ A publicidade infantil tem se debatido entre atender as demandas de dois destinatários, porque precisa atingir os desejos da criança sem perder de vista que o poder financeiro, em geral, pertence ao adulto, conforme estudos de Ramos, Panozzo e Lazaretti (2011).

${ }^{6}$ Sigla originada do francês para Fédération Internationale de Football Association. É um órgão internacional que regula a prática do futebol e é mais conhecida pelo acrônimo FIFA.

${ }^{7}$ Para Bakhtin, como o receptor não é um destinatário pacífico que se limita a compreender o locutor, um enunciado é sempre acompanhado de uma atitude responsiva, ou seja, pressupõe uma resposta do(s) outro(s) a quem o enunciado se dirige. Segundo Bakhtin, "o ouvinte que recebe e compreende a significação (lingüística) de um discurso adota simultaneamente, para este discurso, uma atitude responsiva ativa" (1997, p. 290). Esta atitude pode ocorrer imediatamente após a compreensão de um enunciado como pode também permanecer muda durante um tempo. Entretanto, conforme argumenta Bakhtin, "cedo ou tarde, o que foi ouvido e compreendido de modo ativo encontrará um eco no discurso ou no comportamento subseqüente do ouvinte" (op. cit. p. 291, grifo do autor). É o que ele chama de compreensão responsiva de ação retardada.

${ }^{8}$ Imagem disponível em:

http://portaldoprofessor.mec.gov.br/storage/discovirtual/galerias/imagem/0000000803/0000014978.jpg

Acesso em 15/11/2010

${ }^{9}$ Os autores reconhecem que "a compreensão não pode ser ensinada, uma vez que depende, entre outras coisas, de processos cognitivos internos ao indivíduo, ainda pouco conhecidos". Entretanto, acreditam que a intervenção pedagógica pode facilitar e promover o desenvolvimento efetivo da habilidade de compreensão oral. (ALMEIDA FILHO e EL DASH, 2002, p. 2).

${ }^{10}$ Sugerimos questões a serem discutidas por alunos de nível intermediário de proficiência na língua. As questões podem, no entanto, ser simplificadas, a fim de serem realizadas por alunos de nível básico.
}

\section{6) Referências}


ABDALA JUNIOR, Roberto. "O cinema na conquista da América: Um filme e seus diálogos com a história”. Revista Brasileira de Educação. v. 13, n. 37, 2008.

ALMEIDA FILHO, J.C.P. e EL DASH, L. G. "Compreensão de Linguagem Oral no Ensino de Língua Estrangeira". Revista Horizontes de Lingüística Aplicada, LET/UnB, vol. 01, p. 19-37. 2002.

ANDRADE, Carlos Augusto Baptista de. "HQs: Gênero narrativo de múltiplas linguagens". In: MICHELETTI, Guaraciaba (org.). Enunciação e Gêneros Discursivos. São Paulo, Cortez, 2008.

BAKHTIN, Mikhail. Estética da criação verbal. Traduzido por Paulo Bezerra. 4 ed. São Paulo: Martins Fontes, 2003.

BAKHTIN, Mikhail. Marxismo e Filosofia da Linguagem. $8^{a}$ ed. São Paulo. Editora Hucitec. 1997.

BERNARDET, Jean-Claude. O que é cinema. São Paulo: Brasiliense, 2000.

CHOMSKY, Noam. Linguagem e mente. Brasília: Universidade de Brasília, 1998.

FARACO, Carlos Alberto e outros. Uma introdução a Bakhtin. Curitiba, Hatier, p. 55-57, 1988.

FRANCHI, Carlos. "Linguagem - Atividade constitutive". In: Caderno de Estudos Lingüisticos, (22). Campinas. UNICAMP. p. 9-39, 1992.

HALL, J.K. e VERPLAETSE, L.S. "The development of second and foreign language learning through classroom interaction". In: HALL, J.K. e VERPLAETSE, L.S. (Orgs.). Second and foreign language learning through classroom interaction. London. Lawrence Erlbaum Associates, p. 1-20, 2000.

KRASHEN, S. Principles and Practice in Second Language Acquisition. Oxford: Pergamon Press, 1982.

KRASHEN, Stephen D. The input hypothesis: Issues and implications. London: Longman, 1985.

LARROSA BONDIA, Jorge. "Notas sobre a experiência e o saber de experiência". In: Revista Brasileira de Educação. n. 19, 2002. Disponível em: http://www.anped.org.br/rbe/rbedigital/RBDE19/RBDE19_04_JORGE_LARROSA_B ONDIA.pdf Acesso em 04/10/2010.

MARCUSCHI, Luiz Antonio. "Gêneros textuais: definição e funcionalidade". In: DIONÍSIO, Angela Paiva; MACHADO, Anna Rachel; BEZERRA, Maria Auxiliadora. Gêneros textuais \& ensino. 2. ed. Rio de Janeiro: Lucerna, 2003. 
PINTO, Abuêndia. (1999). "Parâmetros Curriculares Nacionais: Influência no Ensino/Aprendizagem de Língua Estrangeira". In.: MARCUSCHI, E. (org.). Formação do Educador, Avaliação e Currículo. Recife: Ed. UFPE.

SANTOS, Claudia Melissa Neves. Trailer: Cinema e publicidade no mesmo rolo. Dissertação. Mestrado em Comunicação Social. Universidade Federal Fluminense. Niterói, 2004.

SALDANHA, Carlos Saldanha. Entrevista concedida a Moviebox no Telecine Premium e exibida em 16/07/2010. Disponível em: http://www.vejatv.com/video-13574.A-erado-gelo-Ice-Age-Carlos-Saldanha.html. Acesso em 01/10/10.

RAMOS, Flávia B; PANOZZO, Neiva S. P.; LAZARETTI, Maurice. Publicidade na revista Recreio: configuração do consumidor infantil. 2011. Revista Nonada. V. 1, no 16, 2011. Disponível em http://seer.uniritter.edu.br/index.php/nonada/article/viewFile/347/219. Acesso 20/06/2012.

ROIZ, Miguel. La sociedad persuasora: control cultural y comunicación de masas. Barcelona: Paidós, 2002.

VIGOTSKI. L.S. A formação social da mente: o desenvolvimento dos processos psicológicos superiores. Organizado por Michael Cole (et al.) e traduzido por José Cipolla Neto, Luís Silveira Menna Barreto, Solange Castro Afeche. 7.ed. São Paulo: Martins Fontes, 2007.

VIGOTSKI, L. S. Pensamento e linguagem. Trad. Jefferson Luiz Camargo. 4 ed. São Paulo: Martins Fontes, 2008. 